\title{
Effects of Different Extraction Solvents on Oil Extracted from Jatropha Seeds and the Potential of Seed Residues as a Heat Provider
}

\author{
Yadessa Gonfa Keneni ${ }^{1} \cdot$ Legesse Adane Bahiru ${ }^{2} \cdot$ Jorge Mario Marchetti ${ }^{1}$ (D)
}

Received: 29 June 2020 / Accepted: 30 October 2020 / Published online: 9 November 2020

(C) The Author(s) 2020

\begin{abstract}
The present study focuses on the determination of oil contents of thirteen different jatropha seed collections from Ethiopia. The oil was extracted with a Soxhlet extractor using n-hexane which was selected out of four different solvents: diethyl ether, ethanol, n-heptane, and n-hexane. Cotton and thimble were used as filter for the extractions. Some properties of the oil of Chali seed collection and a sample of mixed oils (a mixture of equal volume of oils from thirteen different seed collections) were determined. The energy contents of selected de-oiled jatropha seed residues were also estimated. In the extraction with cotton and thimble, the largest percentage of oil yield was obtained from Dana seed (48.29\%) and Chali seed (45.79) collections, respectively. The acid value $(1.32 \mathrm{mg} \mathrm{KOH} / \mathrm{g})$ and percentage of free fatty acids (\%FFA) $(0.66 \%)$ of Chali seed oil were lower than the acid value $(2.12 \mathrm{mg} \mathrm{KOH} / \mathrm{g})$ and \%FFA (1.06\%) of the mixed oil, and thus, the former oil is more suitable for alkaline-catalyzed biodiesel production. The iodine values of both Chali seed oil $(116.02 \mathrm{~g} / 100 \mathrm{~g})$ and mixed oil $(109.24 \mathrm{~g} / 100 \mathrm{~g})$ did not exceed the maximum standard for biodiesel according to the European EN 14214 specification, and the oils could be used for biodiesel production. The gross calorific values of de-oiled jatropha seed residues after oil extraction were found to range from 18.57 to $24.03 \mathrm{MJ} / \mathrm{kg}$, and with the average value of $19.64 \mathrm{MJ} / \mathrm{kg}$. Thus, the de-oiled seed residues can be used as the source of heat.
\end{abstract}

Keywords Biofuel $\cdot$ Biomass $\cdot$ Calorific value $\cdot$ Jatropha curcas L. · Oil yield · Solvent extraction

\section{Introduction}

Jatropha curcas L. is one of the 170 species of genus Jatropha which belongs to the family Euphorbiaceae. The species has many common names in different regions such as the physic nut, barbados nut, curcas bean, purging nut, and jatropha [1], and the name jatropha is frequently used to refer to the species $[2,3]$. Jatropha (J. curcas L.) is a semievergreen perennial tree or shrub, which can reach a height of 3 to $6 \mathrm{~m}$, but it can attain a height of 8-10 m under favorable conditions [4]. It is native to Central America and has naturalized in many tropical and sub-tropical areas including Asia, Africa, and North America [5]. Originating in the Caribbean, jatropha has been spread as a useful hedge plant to Africa and Asia by Portuguese merchant, and now the plant is found

Jorge Mario Marchetti

jorge.mario.marchetti@nmbu.no

1 Faculty of Sciences and Technology, Norwegian University of Life Sciences, Drøbakveien 31, 1432 Ås, Norway

2 Department of Chemistry, Hawassa University, Hawassa, Ethiopia abundantly in many tropical and sub-tropical regions of the world $[4,5]$.

Different parts of jatropha plant have various uses, and thus, it is considered as a multipurpose shrub $[2,6]$. Jatropha has the potential to be used for the production of biodiesel, cleaning agents, cosmetics, dyes, organic fertilizers, and different medicines [6]. Jatropha seeds are rich in oil that is not edible due to the presence of a toxic compound, the phorbol ester, and thus, the oil has become a very attractive source of biodiesel [7]. Biodiesel is a renewable, biodegradable, and non-toxic alternative to fossil fuels. Production of biodiesel from non-edible oils such as jatropha oil has been given due consideration during the last decade as using such oils for energy sources does not directly compete with the food market [8]. In addition to the oil, which is used as the feedstock of biodiesel, the de-oiled jatropha seed residues can be used as a solid biofuel [9].

The oil contents of jatropha seed and seed kernel could range from 20 to $60 \%$ and 40 to $60 \%$, respectively [10]. The oil contents of the seeds may vary from one growing region to another [11] and for different agro-ecological zones [12]. Several reports indicated the existence of performance variation in oil content and quality for jatropha due the differences 
of environment factors such as temperature, rainfall, light availability, and soil nutrients, and the genotypic variations [12-14].

One of the important steps in biodiesel production from plant oils is oil extraction. The three most commonly employed conventional oil extraction methods are mechanical, chemical/solvent, and enzymatic extraction methods [8]. Besides these, accelerated solvent extraction, supercritical fluid extraction, and microwave-assisted extraction methods are frequently used [15]. Each oil extraction method has its own advantages and limitations. For instance, extraction of oil from jatropha seeds using n-hexane as solvent results in the largest percentage oil yield compared to mechanical and enzymatic extractions. However, using hexane as extraction solvent has negative environment impacts [8]. Microwaveassisted extraction is comparable with other alternative modern extraction techniques in terms of its simplicity and using low-cost equipment. But the requirement of additional processing of the oil (filtration or centrifugation) to remove the solid residues and the possibilities of lipid oxidation due to its higher energy are the limitations of this extraction method [15]. Oil extraction with enzymatic method is ecofriendly, but it takes longer time as the rate of oil extraction by this method is very slow compared to that of the solvent extraction methods [16]. Moreover, in supercritical fluid extraction, oil produced has very high purity and the time needed is also very short; however, the operating and investment cost is higher [15].

In commercial oil extraction, solvent extraction and mechanical pressing are the most commonly used methods [8], but solvent extraction is more efficient in terms of oil recovery [17]. In solvent extraction, the percentage yield of the oil can be affected by the type of solvent used, particle sizes of the meal, extraction temperature, solvent to solid ratio and extraction time $[6,18]$, and the moisture contents of the solid to be extracted [19].

Different solvents can be used to extract oil from plant seeds. Hexane, petroleum ether, diethyl ether, ethanol, n-heptane, isopropanol, acetone, chloroform, methanol, and 1butanol were some of the most commonly used and reported solvents for oil extraction [17, 20, 21]. The oil extraction efficiency, environmental impacts, and the renewability of different extraction solvents can be different. It has been also reported that different solvents yield different natural compounds from a given material, and thus, the extract composition can differ from solvent to solvent [22]. Therefore, selection of a solvent for oil extraction is one of the most important steps in oil extraction by chemical methods [23]. Generally, hexane is the most commonly used solvent for the extraction of oils from plant sources due to its low boiling temperature and easy recovery from the extract, and since most oils are soluble in hexane [15].
Soxhlet extraction is the most widely utilized solid-liquid extraction technique in research, and it is one of the most traditional techniques still being used. It is a popular method and used as a reference for several existing modern extraction techniques [22]. However, compared to the newly developed modern oil extraction techniques such as supercritical fluid extraction, microwave-assisted extraction, and accelerated solvent extraction, it has several limitations which include long extraction times and large solvent losses, and its temperature is limited by the boiling point of the selected solvent [24].

Except a few researches on oil extraction using hexane and petroleum ether, no research has been reported on oil extraction from jatropha seeds from different parts of Ethiopia by drying the seeds at an appropriate temperature [25] and using different solvents. The objective of the present research was to determine the amount of oil that could be extracted from different jatropha seed collections from Ethiopia using different pre-treatments and solvents and measure the energy contents of the de-oiled seed residues.

The current paper presents some new issues that have not been reported in the other studies on oil extraction from jatropha seed collection from Ethiopia. Firstly, in the present study, the whole seeds (seeds with seed coat) were dried before oil extraction based on the results of our previously published work on jatropha seed drying [25]. In this seed drying study, drying the whole seeds at $80^{\circ} \mathrm{C}$ for $48 \mathrm{~h}$ was found to reduce the moisture contents of the seeds to below $1 \%$, and this could eliminate heating of the oil at higher temperature after extraction to remove the residual moisture. Secondly, cotton was used as filter in the first-round oil extraction to test the potential of cotton to be used as an alternative filter in Soxhlet extraction in areas where access to extraction thimble is a problem, particularly in developing countries. Thirdly, up to our knowledge, in the previous oil extractions from jatropha seeds from Ethiopia, only hexane [11] and petroleum ether [26] were used as solvents. In the current study, four organic solvents (diethyl ether, ethanol, n-heptane, and n-hexane) were used as solvent and compared in terms of the percentage of oil they extracted from a selected seed collection.

\section{Materials and Methods}

\section{Materials}

Thirteen different seed collections of jatropha (J. curcas L.) used for the present study were collected from Ethiopia. From these, seven seed collections (Kurkura, Bira, Salmene ${ }_{1}$, Salmene $_{2}$, Salmene 3 , Shekla, and Gerbi) were collected from the north-central part of the country while the rest collections (Dimeka, Chali, Kako, Mulato, Dana, and Awwaaragamaa) were harvested from the southern part. These collection sites 
were the areas where large cultivation of jatropha has been practiced by the local farmers.

After collecting jatropha fruits, the seeds were recovered from the fruits mostly with hands by splitting open the fruit shells, and rarely by cracking the fruits carefully using small stones. The procedures used to remove the seeds from the fruits were adopted from the practices of the local farmers (farmers living around the seed collection areas). The collected seeds were air- and sun-dried for storage. Then, the dried seeds were transported to the Biodiesel Laboratory of Norwegian University of Life Sciences (NMBU), Faculty of Science and Technology, and stored at room temperature (about $20^{\circ} \mathrm{C}$ ) until used for oil extraction. The seven seed collections from the north-central part of the Ethiopia were collected in the first week of July 2016, stored in the laboratory of NMBU in first week of August 2016, and the oil extraction experiments were carried out in August and September 2016. In the same season and months of 2017, the six seed collections from southern part the country were collected, stored at NMBU, and extracted. Hence, the time taken from seed collection to oil extraction for all seed collection was about 3 months. Information of the seed collection sites, maturation stages of the fruits, and the respective seed collection years are presented in Table 1 .

The seeds at storage were dried before oil extraction, using a heating furnace (Narbetherm P300, Germany) by placing the seed samples on Pyrex Petri dishes $(100 \times 15 \mathrm{~mm})$. The dried seeds were crushed using mortar and pestle for oil extraction. Moreover, a Plain Jacket bomb calorimeter (Model 1341, Parr Instrument Company, USA) was used to measure the energy contents of the de-oiled seed residues produced after oil extraction.

The organic solvents (diethyl ether, absolute ethanol, nheptane with purity higher than $99 \%$, and $\mathrm{n}$-hexane anhydrous with purity of $95 \%$ ) used for oil extraction were purchased from Sigma-Aldrich, Germany. The diethyl ether, ethanol, and chloroform with purity higher than $99 \%$ and purchased from Sigma-Aldrich, phenolphthalein indicator (ACS reagent) from Merk, wijs solution for determination of iodine number (Merk KGaA, Germany), potassium hydroxide ( $0.1 \mathrm{~N}$ in ethanol) from VWR Chemicals BDH, and the starch potato (VWR International Ltd., Belgium) used for the determination chemical properties of the oil samples were analytical reagent grades. The other reagents used for the determination of the properties of the oil samples were sulfuric acid with purity of 98\% and purchased from Merk, potassium iodide, and sodium thiosulfate $\left(\mathrm{Na}_{2} \mathrm{SO}_{3} .5 \mathrm{H}_{2} \mathrm{O}\right)$, and they were also analytical reagent grades.

\section{Experimental Procedures}

Prior to oil extraction, the whole seeds (WS) at storage were dried in a heating furnace before crushing them. Accordingly, the WS with their seed coats were placed on Petri dishes and dried in the furnace at $80^{\circ} \mathrm{C}$ for $48 \mathrm{~h}$ to reduce their moisture content to the minimum following the previously published work [25]. According to Subroto [27], exposing the seed coat unprotected seed to temperatures higher than $60{ }^{\circ} \mathrm{C}$ might cause jatropha oil peroxidation, and thus, in the current work, drying the WS with its seed coat and crushing it just before oil extraction was preferred.

After drying, the WS were crushed mechanically by hand using mortar and pestle. Then, the particle sizes of the crushed seeds (PSCS) were estimated using three different stainless steel sieves with openings of $500 \mu \mathrm{m}, 1 \mathrm{~mm}$, and $2 \mathrm{~mm}$ woven cloth (control group, 15-D2245/J, 15-D2215/J, and 15D2185/J) following the studies published elsewhere [25]. Accordingly, the pulverized seeds used for this experiment was a mixture of four different particles sizes. The average proportions (\%) of different PSCS: PSCS $>2 \mathrm{~mm}, 2 \mathrm{~mm}>$ PSCS $>1 \mathrm{~mm}, 1 \mathrm{~mm}>$ PSCS $>500 \mu \mathrm{m}$, and PSCS $<500 \mu \mathrm{m}$, were about $14.95 \pm 8.2,29.96 \pm 4.38,35.32 \pm 10.5$, and 19.77 $\pm 4.74 \%$, respectively. The particle size of the seeds used in the current study was determined as it is one of the important factors that affect the oil extraction process using solvents. An appropriate particle size of seeds may be needed to obtain the highest oil yield using a solvent, and this may also vary depending on the nature of the oilseed and its oil content [28]. Larger particles have a smaller surface area per unit volume, and this may result in reduced accessibility of the oil to the solvent. Very fine and powder-size particles have a larger surface area per unit volume, but the fine particles that contain oil may stick together and prevent the free interactions between the solid and solvent $[18,28]$.

All seed samples were weighed using a sensitive electronic balance having $0.0001 \mathrm{mg}$ accuracy (AD, GR-202-EC, A\&D Instruments, Japan). Oil extraction from the crushed seeds (CS) was performed with a Soxhlet extractor having an extractor column and oil-collecting round bottom flask of $200 \mathrm{ml}$ and $250 \mathrm{ml}$, respectively. In the first-round oil extraction processes, cotton was used as filter due to its easy availability and cheaper cost compared to the extraction thimbles. Two types of thimbles were also used for the extraction: thimble with single thickness $(37 \times 130 \mathrm{~mm})$ and a relatively thicker thimble (Hahnemühle FineArt, Germany, $40 \times 150 \mathrm{~mm}$ ). Heating mantle (LabHeat, SAF, KM-MER $250 \mathrm{ml}$ ) was employed during oil extraction to heat the round bottom flask of the Soxhlet extractor at the temperature around the boiling points of the extraction solvents. A rotary evaporator (Rotary Vapo R-3, Butchi Labortechnik AG, CH-9230, Switzerland) with a vacuum pump (Shanghai Eyela CO. LTD Aspirator A.1000S, China) was also used to separate the oil and the solvents after oil extraction.

The oil extraction experiments involved three round extractions with different purposes. In the first-round oil extraction experiments, Salmene 3 seed collection was extracted using 


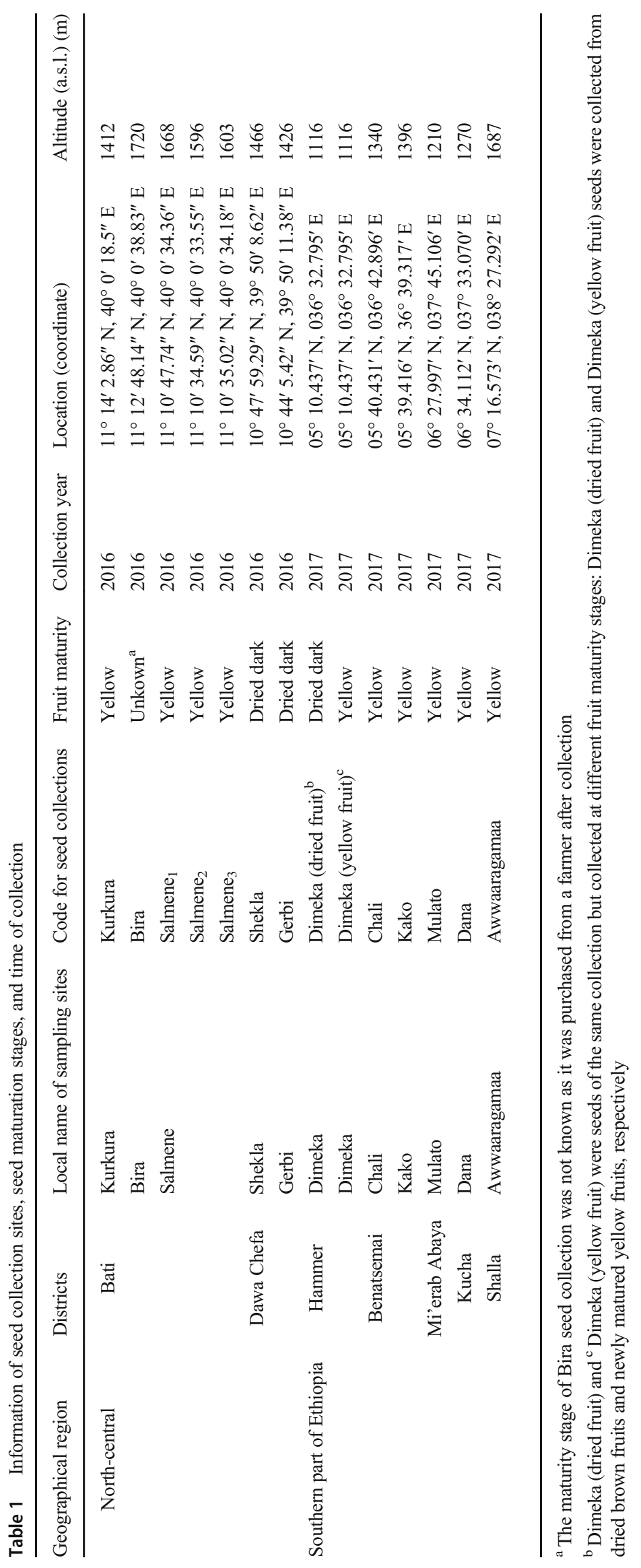


four different solvents (diethyl ether, ethanol, n-heptane, and n-hexane) and cotton as filter to identify the most efficient solvent for oil extraction in terms of the percentage of oil extracted. Salmene 3 seed collection was selected for the indicated experiment as it was collected from yellow fruits. It has been reported that maximum physiological quality and lipid content of jatropha seeds occur at the physiological seed maturity, which corresponds to the seeds obtained from yellow fruits $[29,30]$. In the second-round oil extractions, all the thirteen seed collections were extracted using the previously selected solvent and cotton. This experiment was carried out to determine the amount of oil (\%) that could be extracted from the respective seed collections. After determining the average oil extracted from the seed collections from the north-central and the southern part of the country separately, the seed collections from southern Ethiopia were selected for the third-round oil extraction with thimble for further investigations as larger amount of oil (\%) was obtained from these collections.

In all experiments of oil extraction, $50 \mathrm{~g}$ dried CS were used, except in the case of oil extraction from non-dried Dana seed collection in which non-dried WS and CS (50 g of each sample) were extracted using hexane and ethanol as solvents, and cotton as filter. The amount of the solvents used for all experiments was also $240 \mathrm{ml}$. Accordingly, the ratio of the amount of solvent ( $\mathrm{ml}$ ) to the gram of crushed seeds used in the current experiments was $4.8: 1$. The ratio of the extraction solvent to the weight of crushed seeds for this study was modified from a related study by Sayyar et al. [18].

Oil sample from the selected seed collection (oil from Chali seed collection) and a sample of mixed oils (the mixture formed from oils of all the thirteen seed collections) were characterized. The energy contents of the selected de-oiled seed residues produced after oil extraction with hexane using cotton were also determined by bomb calorimeter. Figure 1 shows the schematic diagram of jatropha seed processing for oil extraction, oil extraction procedures, and the postextraction process. The procedures in the schematic diagram (Fig. 1) and other additional experiments of oil extraction from Kako and Salmene 2 seed collections are described in the next part.

\section{Extraction of Oil from the Seeds}

Oil Extraction Using Cotton During the oil extraction from Salmene $_{3}$ to identify the solvent that could extract the largest amount (\%) of oil from the seeds, the WS were dried, crushed, and extracted with diethyl ether, ethanol, heptane, and hexane using cotton as filter. Depending on the amount of oil (\%) extracted from Salmene 3 using these solvents, the solvent that extracted the largest amount of oil was selected. Then, the samples of all seed collection were treated with the selected solvent. Accordingly, all the thirteen seed collections were extracted with the selected solvent using cotton after drying the WS and crushing them [25].

In oil extraction with cotton, the seed samples were placed in a Soxhlet extractor column in between two cotton layers with uniform thickness. After adding $240 \mathrm{ml}$ of the respective solvents to the round bottom flask, the flask was placed on the heating mantle and all the Soxhlet extractor parts were fitted to each other to complete the full setup. Then, the solvents were heated to their respective boing points for the oil extraction to occur. The oil extraction proceeded until five cycles of washes to occur. In this paper, the extraction duration is expressed in
Fig. 1 Schematic diagram for jatropha seed collection, oil extraction, and post-extraction processes

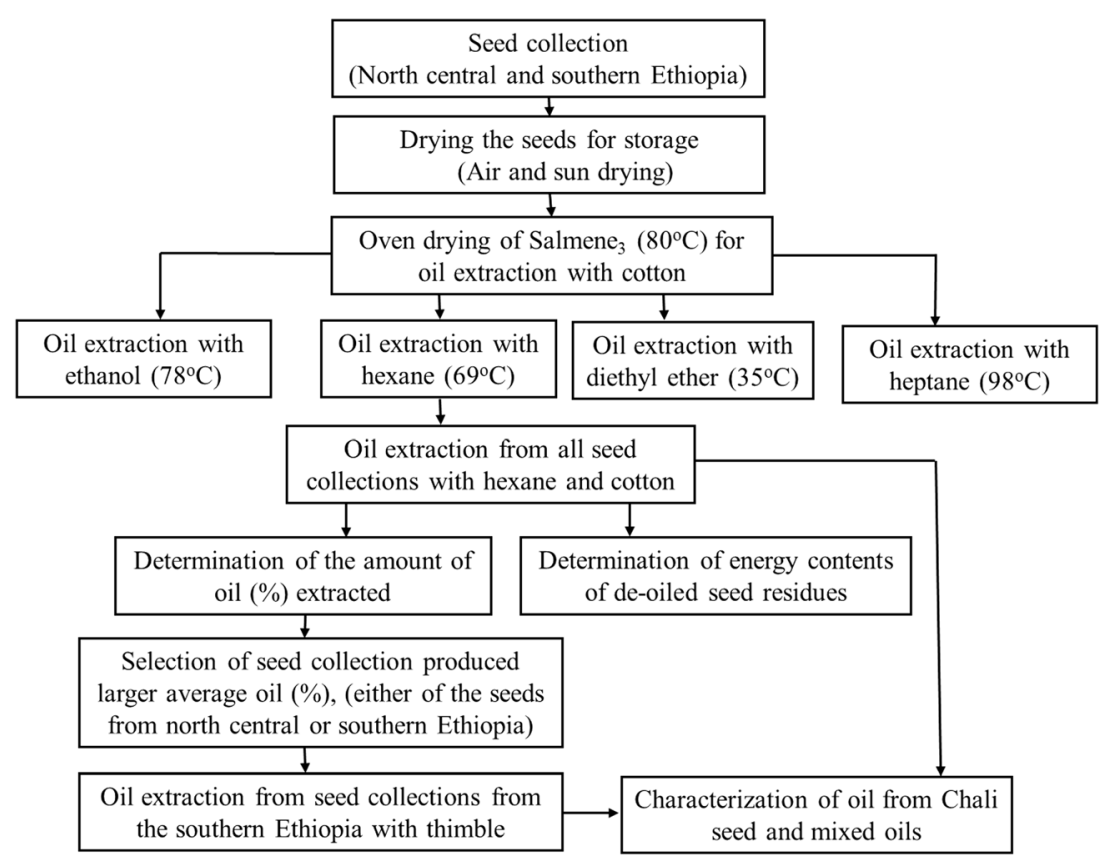


terms of the number of cycles of washes occurred using the Soxhlet extractor. Based on the results of the pilot experiments performed to check the number of cycles of washes that should be applied during the oil extraction experiments, to extract almost all the oil available for extraction from the crushed seeds using different solvents, five and ten cycles of washes were employed for the extraction with cotton and thimbles, respectively. The average time taken for one cycle of wash to occur for both the extractions with cotton and thimble was about $50 \mathrm{~min}$. By using the results from the pilot experiments, it was also checked that the oil extraction with cotton had good reproducibility in terms of the oil yield obtained.

After extraction, the extract (the mixture of oil and solvent) was filtered using Whatman filter paper. The solvents were recovered from the extract using a rotary evaporator with vacuum pump by heating the extract to the temperature around the boiling points of solvents for $2.5 \mathrm{~h}$. After the removal of the solvents, the remaining oil was weighed and its amount was determined in terms of the percentage of oil yield, using Eq. (1) which was also used in the previous related studies [6, 11]. This equation was also used to determine the percentage of oil yield from all seed samples presented in this paper.

Percentage of oil yield $(w / w)=\frac{W_{\text {Oil }}}{W_{\mathrm{CS}}} \times 100$

where $W_{\text {Oil }}$ is weight of oil obtained $(\mathrm{g})$ using an extraction method and $W_{\mathrm{CS}}$ is the weight of crushed seed (g) just before oil extraction.

Besides extracting the oil by drying the whole seeds (WS) and crushing them, the non-dried WS and crushed seeds (CS) of Dana seed collection were extracted with hexane and ethanol using cotton as filter, and by employing five cycles of washes. This experiment was performed to check if hexane and ethanol or either of them could extract any oil from the whole seeds. The experiment was also aimed to compare the amount oil (\%) that could be extracted from the non-died CS (crushed seeds from non-dried WS) using the two solvents.

From the seven seeds collected from the north-central Ethiopia, Salmene 2 which was also collected at a physiological maturity stage of the fruit (from yellow fruit) was selected for the storage temperature experiments. In this case, three samples of Salmene 2 were stored at three different temperatures to investigate the effects of the storage temperature on the percentage of oil that could be extracted. Accordingly, each of the three samples was placed at the room temperature $\left(20{ }^{\circ} \mathrm{C}\right)$, cool temperature $\left(4{ }^{\circ} \mathrm{C}\right)$, and freezing temperature $\left(-18^{\circ} \mathrm{C}\right)$, respectively, for 18 months (from September 2016 to February 2018). After the indicated period, triplicated samples of the seed stored at the respective temperatures were dried [25], crushed, and extracted with a Soxhlet extractor using hexane and cotton.
Oil Extraction Using Thimbles Triplicated WS samples from the seeds from southern Ethiopia were dried, crushed, and extracted using the selected solvent and thimble with single thickness $(37 \times 130 \mathrm{~mm})$ for ten cycles of washes. Moreover, from the seeds collected from southern Ethiopia, Kako seed collection was purposively selected for oil extraction by ethanol using thicker thimble $(40 \times 150 \mathrm{~mm})$ and cotton. The experiment was conducted to compare the amount of oil (\%) that could be extracted by ethanol and thimble, and also to investigate the effects of extraction time (cycles of washes) with thimble on the amount of oil (\%) extracted. Ethanol was selected for the extraction of oil from Kako seed collection as ethanol is non-toxic and renewable, and it is preferable in terms of the environmental health and utilization of biosolvent which is renewable [31].

\section{Characterization of the Extracted Oils}

Two different oil samples: the sample from Chali seed collection extracted with Soxhlet extraction using thimble (Chali oil) and a sample of mixed oils (the mixture formed by mixing equal volumes of oils extracted from all the thirteen seed collections), were characterized for physical and chemical properties. The Chali oil was selected for analysis as the amount of oil $(\%)$ extracted from this collection using hexane and thimble was found to be the largest of the oils extracted from all the six jatropha seeds collected from southern Ethiopia using the same method. The properties selected were acid value, percentage of free fatty acids (\%FFA), iodine value, saponification value, and oil density. The selection of these oil properties was based on the previous related studies [26, 32, 33]. During oil analyses, the experiments were done twice for all oil properties and the average values of the two experiments were reported in this article.

Acid Value The acid value (AV) and percentage of free fatty acid (\%FFA) of both oil samples were determined following the procedures used by Asmare and Gabbiye [32] to determine these parameters for castor bean oil. Accordingly, $25 \mathrm{ml}$ of diethyl ether and ethanol (1:1) mixture was added to $5 \mathrm{~g}$ of oil in a 250-ml conical flask and shacked well. After adding 5 drops of phenolphthalein indicator, the solution was titrated with $0.1 \mathrm{~N}$ ethanolic $\mathrm{KOH}$ with consistent shaking until the end point of the titration was confirmed (change from colorless to pink). The volume of $0.1 \mathrm{~N}$ ethanoic $\mathrm{KOH}(\mathrm{V})$ consumed during the titration was recorded. The total acidity of the sample in $\mathrm{mg} \mathrm{KOH} / \mathrm{g}$ was calculated using the following expression.

$$
\mathrm{AV}=\frac{56.1 * N * V}{W}
$$


where $N=$ the normality of ethanolic $\mathrm{KOH}$ used, $V=$ the volume (ml) of ethanolic $\mathrm{KOH}$, and $W=$ the weight $(\mathrm{g})$ of oil sample.

The \%FFA was also calculated from the acid value of the oil using the following equation.

$\% \mathrm{FFA}=\mathrm{AV} / 2$

lodine Value To determine the iodine value (IV) of the oils samples, the procedures used by Amabye and Bezabh [26] were adopted. Accordingly, $0.25 \mathrm{~g}$ of oil sample was measured and placed in a $250-\mathrm{ml}$ flask, and $20 \mathrm{ml}$ of chloroform was added into the flask to dissolve the oil sample. Then, 20-ml Wijs reagent, the iodine monochloride solution, was added to the mixture using a pipette. The flask was stoppered and kept in a dark place for $1 \mathrm{~h}$ with intermittent shaking. After $1 \mathrm{~h}$, the mixture was taken out of the dark and $10 \mathrm{ml}$ of $15 \%$ potassium iodide solution and $50 \mathrm{ml}$ of distilled water were added and shaken well by inserting the stopper properly to the flask. Then, the liberated iodine was titrated with $0.1 \mathrm{~N}$ sodium thiosulfate $\left(\mathrm{Na}_{2} \mathrm{~S}_{2} \mathrm{O}_{3} .5 \mathrm{H}_{2} \mathrm{O}\right.$ solution) with gently stirring the mixture until the yellow color changed to a light straw. Finally, 5 drops of $1 \%$ starch indicator was added to the mixture and the titration was continued until the blue color disappeared. The blank titration was also conducted side by side to use it in the calculation to determine the parameter.

The iodine value of the oil sample was determined using the following equation.

$\mathrm{IV}=\frac{V_{b}-V_{s}}{W} * 12.69 * N$

where $V_{b}=$ volume $(\mathrm{ml})$ of sodium thiosulfate used for the blank, $V_{s}=$ volume $(\mathrm{ml})$ of sodium thiosulfate used for the sample, $N=$ normality of sodium thiosulfate, and $W=$ the mass of the sample used (g).

Saponification Value The saponification value (SV) was determined according to Ogbunugafor et al. [33]. Fifty milliliters of $0.5 \mathrm{~N}$ ethanolic potassium hydroxide $(\mathrm{KOH})$ was added into a conical flask containing $1 \mathrm{~g}$ of jatropha oil. The flask was connected to the condenser and the mixture was heated to reflux with gentle stirring for $45 \mathrm{~min}$. Then, the mixture was cooled to room temperature, after which, it was titrated with $0.5 \mathrm{~N}$ sulfuric acid $\left(\mathrm{H}_{2} \mathrm{SO}_{4}\right)$ by adding 5 drops of phenolphthalein indicator until the pink color of the indicator just disappeared. The blank test was also carried out under the same conditions. The saponification value of the sample was calculated using the following equation.

$\mathrm{SV}=\frac{V_{b}-V_{s}}{W} \times N \times 56.1$ where $V_{b}=$ volume $(\mathrm{ml})$ of sulfuric acid used for the blank, $V \mathrm{~s}=$ volume $(\mathrm{ml})$ of sulfuric acid used for the sample, $N=$ normality ethanolic potassium hydroxide $(\mathrm{KOH})$, and $W=$ the mass $(\mathrm{g})$ of the sample.

Density The volumetric flask with capacity of $50 \mathrm{ml}$ was dried well before using it for the determination of the densities of the oil samples. The dried flask was placed on a sensitive electronic balance and the reading of the balance with the flask was adjusted to zero. Then, the oil sample was added to the volumetric flasks using pipette until the volume of the oil reached $50 \mathrm{ml}$, and the weight $(\mathrm{g})$ of the oil was recorded. Finally, the density of the oil was determined from the weight reading and the volume of the oil. The measurement was duplicated, and the average value of the measurements was reported. The densities of the oil samples were determined at $20{ }^{\circ} \mathrm{C}$.

\section{Determination of the Energy Contents of the De-oiled Seed Residues}

The energy content of biomass is determined by its calorific value, and the calorific value is influenced by biomass elemental composition, moisture, and ash contents [34]. Upper calorific value (gross calorific value) is the amount of heat per unit of weight released by complete combustion of the fuel (biomass) in the pressure vessel built in the calorimeter under compressed oxygen at $25^{\circ} \mathrm{C}$. In the calorimetric vessel, the sample is totally burned and the values of temperature jump were converted to the net energy value. Net calorific value is the gross calorific value minus the heat of vaporization of water, resulting from the fuel during combustion [9]. Accordingly, after the extraction of oil from the crushed jatropha seeds with cotton, the de-oiled residues of some selected seed samples were dried under fume hood for 5 days. The energy content of de-oiled residue of Kako seed collection that was extracted with ethanol and thicker thimble (by employing five cycles of washes) was also determined for comparison. Then, the upper calorific values (gross calorific values) of the residues were estimated by bomb calorimeter, using benzoic acid as a standard. The objective was to compare the calorific values of different analyzed de-oiled seed residues with each other and with that of other crop residues from literature.

\section{Statistical Analysis}

The data of oil contents of jatropha seed collections from southern Ethiopia that were extracted by thimble with single thickness and that of Salmene, stored at three different temperatures were subjected to the analysis of variance (ANOVA test). Significant difference among the amount of oil produced 
Fig. 2 Percentage of oil extracted from Salmene 3 using different organic solvents and cotton as filter

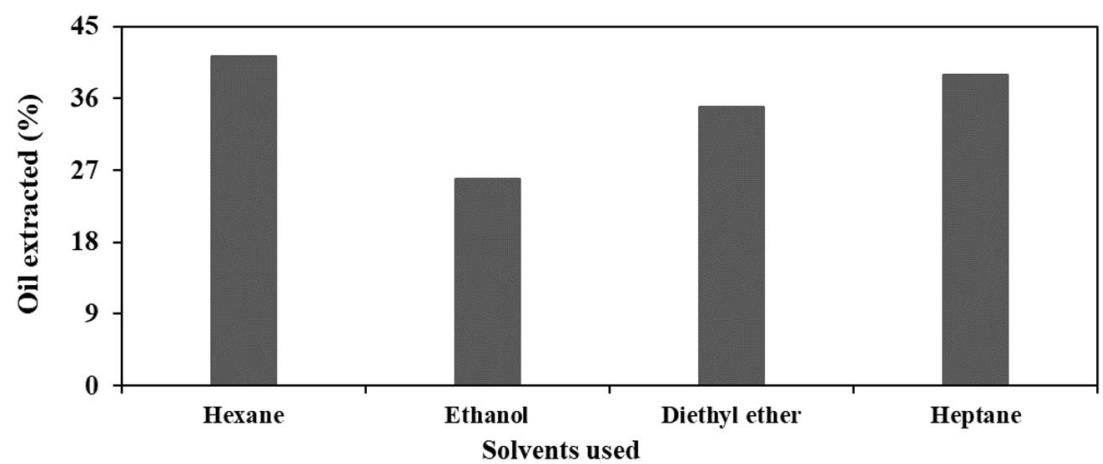

(\%) from the six different seed collections from southern Ethiopia and those of Salmene ${ }_{2}$ stored at three different temperatures, respectively, were analyzed at $p \leq 0.05$. Duncan's post hoc test $(p \leq 0.05)$ was used to determine the homogeneity subsets whenever significant differences existed among the treatments. The statistical software used was SPSS for windows, version 20 .

\section{Results and Discussion}

\section{Extraction of Oil Using Different Solvents}

As it was mentioned in the methodology, Salmene ${ }_{3}$ seed collection was extracted with different solvents using cotton as filter to compare the efficiency of different solvents to extract the oil from CS. Figure 2 shows the percentage of oil extracted from Salmene S $_{3}$ using different organic solvents by employing five cycles of washes. As it can be seen from Fig. 2, in the extraction of oil using four different organic solvents (diethyl ether, ethanol, heptane, and hexane), the percentage of oil extracted using hexane (41.24\%) was found to be the largest. In their comprehensive reviews on oil extraction techniques and biodiesel production technologies, Atabani et al. [35] indicated that oil extraction using $n$-hexane method results in the highest oil yield which makes it the most common solvent used. Most oils are soluble in hexane and this contributed to its superior ability to result in higher yield [15].

Based on the results presented in Fig. 2, hexane was selected as the best solvent in terms of the amount of oil extracted, and thus, it was used for the determination of the oil contents of all collections of jatropha seeds used in this study. However, using ethanol as solvent is more preferable in terms of environmental health and being renewable, because ethanol is environmentally less toxic, and renewable (it can be produced from renewable resources by fermentation of sugarcontaining feeds, starchy feed materials, or lignocellulosic materials) [31].

\section{Extraction of Oil from Different Seed Collections}

\section{Oil Extraction from Crushed Seeds Using Hexane and Cotton}

Table 2 shows the percentage of oil extracted from jatropha seeds collected from the north-central and southern parts of Ethiopia after drying and crushing the seeds. Extraction was done with a Soxhlet extractor using hexane and cotton as solvent and filter, respectively, and by applying five cycles of washes. By using this method, the amount of oil (\%) extracted from the seven seed collections from the north-central part of the country ranged from 26.05 to $41.51 \%$, and the average was found to be $34 \%$. The amount of oil extracted
Table 2 Oil extracted (\%) from jatropha seed collections from north-central and southern Ethiopia, using hexane and cotton

\begin{tabular}{|c|c|c|c|c|c|}
\hline \multirow[t]{2}{*}{ No. } & \multicolumn{2}{|c|}{ Seed collections from north-central Ethiopia } & \multirow[t]{2}{*}{ No. } & \multicolumn{2}{|c|}{ Seed collections from southern Ethiopia } \\
\hline & Seed collection & Oil yield (\%) & & Seed collection & Oil yield $(\%)$ \\
\hline 1 & Kurkura & 31.59 & 1 & Dimeka (dried fruit) & 44.18 \\
\hline 2 & Bira & 31.92 & 2 & Dimeka (yellow fruit) & 36.29 \\
\hline 3 & Salmene $_{1}$ & 26.05 & 3 & Chali & 43.48 \\
\hline 4 & Salmene $_{2}$ & 41.51 & 4 & Kako & 30.66 \\
\hline 5 & Salmene $_{3}$ & 41.24 & 5 & Mulato & 43.86 \\
\hline 6 & Shekla & 34.75 & 6 & Dana & 48.29 \\
\hline \multirow[t]{2}{*}{7} & Gerbi & 30.94 & 7 & Awwaaragamaa & 36.31 \\
\hline & Average & 34.00 & & Average & 40.43 \\
\hline
\end{tabular}


from Salmene, seed collection $(41.51 \%)$ was the largest and that obtained from Salmene ${ }_{1}(26.05 \%)$ was found to be the smallest. For the seed collections from southern Ethiopia (Table 2), the largest percentage oil $(48.29 \%)$ was obtained from Dana seed collection, and the second largest oil yield was found from Dimeka seed collection obtained from dried fruits $(44.18 \%)$. The average oil extracted from the seed collections from southern Ethiopia was calculated to be $40.43 \%$. The smallest oil yield (30.66\%) was obtained from Kako seed collection. The difference in the amount of oil extracted from different seed collections might be due to the existence of some genetic variations among the seed collections and/or relative differences in the environmental conditions of the seed collection regions. It has been reported that drier climate is supposed to improve the oil yield of $J$. curcas seeds. Moreover, phosphorus has been found to be the main requirement for increase in oil yield in the case of castor beans growing in East Africa [36].

In the study of oil extraction from jatropha seeds collected from 40 different sites (provenances) of Ethiopia, Beemnet et al. [11] reported that from the existing Ethiopian jatropha provenances growing in different testing sites, $15.79 \%$ of the provenances demonstrated oil content value of $>35 \%$, $71.05 \%$ between 30 and $35 \%$, and the remaining $13.16 \%$ demonstrated oil content value of $<30 \%$. The authors also wrote that the differences for the oil obtained from jatropha seeds collected from different provenances might be due to the variations of the existing growing conditions and some genetic variations. In their review of the influences of abiotic factors on plant lipids, Singer et al. [13] mentioned that besides plant genotype, seed oil concentration can be affected by the environmental conditions such as temperature, which modifies seed oil concentration and the fatty acid composition through changes in grain filling dynamics and biosynthetic activity.

For the seed collections from southern Ethiopia, the amount of oil extracted from Dimeka seed collected from yellow fruit (36.29\%) was less than that of the seed obtained from dried fruit (44.18\%) (Table 2). The oil yield obtained from Dimeka seed collected from the yellow fruit in the present experiment was in contrary to the values reported by Santoso et al. [37] in which 36.9 and $35.8 \%$ oil was obtained from jatropha seeds (Indonesian genotype) collected from yellow and black-dry fruits, respectively. From the study of oil contents of jatropha seeds collected from Botswana at different fruit maturity stages, Jonas et al. [30] also reported the highest oil yield, oil with the least FFA\% level, and biodiesel with the highest energy content for jatropha seeds collected from yellow fruits.

During seed collection from southern Ethiopia (in July 2017), the majority the fruits of jatropha plants at the Dimeka site had dried and turned to brown due to lower altitude and dry climate of the area, and only a few lately produced fruits were found at the yellow stage. Thus, both seeds
Table 3 Oil extracted from non-dried whole seeds (WS) and crushed seeds (CS) of Dana seed collection using hexane and ethanol

\begin{tabular}{llll}
\hline No. & Solvent used & Types of seed extracted & Oil yield (\%) \\
\hline 1 & Hexane & WS & 0 \\
& & CS & 41.82 \\
2 & \multirow{2}{*}{ Ethanol } & WS & 0 \\
& & CS & 29.93 \\
\hline
\end{tabular}

from the lately produced yellow fruits and those from dried fruits were collected from the Dimeka site and used for the experiment. Therefore, the lower oil yield of Dimeka seeds collected from the yellow fruit compared to that obtained from dried fruit might be due to the lately produced abnormal yellow fruits collected and used for the experiment.

When the amount of oils extracted (\%) from the seed collections from north-central Ethiopia were compared with those obtained from the seed collections from southern Ethiopia (Table 2), generally, the average oil extracted from the seed collections from southern Ethiopia (40.43\%) was greater than that of the seed collections of north-central Ethiopia (34\%). The maximum $(48.29 \%)$ and minimum $(30.66 \%)$ oil extracted from the seed collections from southern Ethiopia were also greater than the maximum $(41.51 \%)$ and minimum $(26.05 \%)$ oil obtained from those of the northcentral part of the country, respectively. The difference in the amounts of oil extracted from the seed collections from the southern and north-central parts of the country might be due to the differences of the growing conditions (altitude, climatic, and soil conditions) and some genetic differences of the jatropha plants growing in the southern and northcentral parts of the country $[11,13,14]$.

Based on the average oil extracted (\%) from jatropha seed collections from the two geographical regions (north-central and southern parts) of Ethiopia, the seed collections from the southern part of the country which gave larger average oil $(40.43 \%)$ were selected to be extracted with extraction thimble for further investigations.

\section{Oil Extraction from the Whole and Crushed Dana Seed Collection}

The amount of oil extracted from crushed non-dried Dana seed collection with cotton using hexane $(41.82 \%)$ was larger than the one extracted from the same seed with ethanol $(29.93 \%)$. No oil was obtained when the non-dried WS was extracted with hexane and ethanol, respectively. Table 3 shows the amount of oil extracted from non-dried WS and CS of Dana seed collection using hexane and ethanol as solvent, cotton as filter, and by applying five cycles of washes. From Table 2 and Table 3, it can be seen that the amount of oil 
Fig. 3 Mean oil extracted (\%) from seeds collected from southern part of Ethiopia using hexane and thimble with single thickness and extracted by ten cycles of washes. Bars show means \pm SE (standard errors) and different letters indicate significant differences among the mean oil extracted from the seed collections (Duncan's post hoc test at $p \leq 0.05$ )

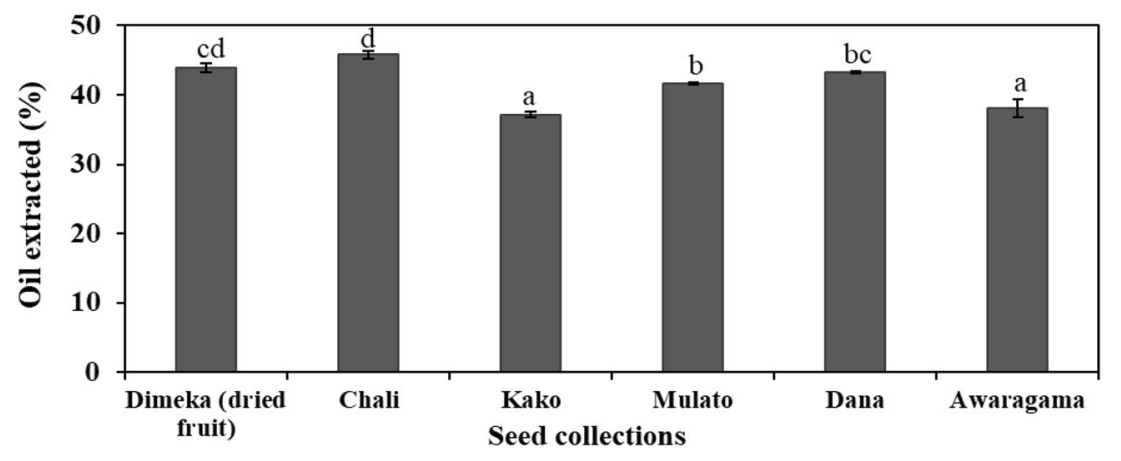

extracted from the WS of Dana seed collection dried, crushed, and extracted using hexane and cotton $(48.29 \%)$ was greater than the amount of oil extracted from the non-dried CS of the same seed $(41.82 \%)$ with similar methods of extraction. In line with this result, in the extraction of oil from Moringa (Moringa oleifera) seeds with a Soxhlet extractor using hexane, Omosuli et al. [38] obtained the oil yield of 30.30, 32.21, and $33.11 \%$ from the milled seed flour of raw (non-dried), sun-dried, and oven-dried Moringa seeds, respectively. From the results of the current experiment, it could be suggested that drying the WS of jatropha before crushing it for oil extraction might increase the leaching of the oil from the pulverized seeds during oil extraction.

\section{Oil Extraction from Seeds from Southern Ethiopia Using Thimble}

Figure 3 presents the mean oil extracted (\%) from jatropha seeds collected from southern Ethiopia using hexane and thimble with single thickness. As it can be seen from Fig. 3, the mean oil extracted ranged from $37.14 \pm 0.46$ to $45.79 \pm$ $0.54 \%$. The mean oil extracted from Chali seed collection $(45.79 \pm 0.54 \%)$ was not significantly different $(p \leq 0.05)$ from that of Dimeka seed collected from dried fruit (43.91 \pm $0.71 \%)$. However, it was significantly larger $(p \leq 0.05)$ than the mean oil extracted from of Kako $(37.14 \pm 0.46 \%)$, Awwaaragamaa (38.04 \pm 1.24$)$, Mulato $(41.61 \pm 0.21)$, and Dana $(43.29 \pm 0.12)$ seed collections. The mean oil extracted from Kako (37.14 $\pm 0.46 \%)$ and Awwaaragamaa (38.04 \pm $1.24 \%)$ were significantly lower $(p \leq 0.05)$ than those of the other seeds collected from southern Ethiopia and extracted with thimble with single thickness. Moreover, the overall

Table 4 Kako seed collection extracted by ethanol using thinker thimble and cotton, and with different cycle of washes

\begin{tabular}{llll}
\hline No. & Filter used & Cycles of wash & Oil yield $(\%)$ \\
\hline 1 & Thicker thimble $(40 \times 150 \mathrm{~mm})$ & 5 & 11.99 \\
2 & Thicker thimble $(40 \times 150 \mathrm{~mm})$ & 10 & 26.73 \\
3 & Cotton & 5 & 28.17 \\
\hline
\end{tabular}

average oil extracted (\%) from all the six jatropha seeds shown in Fig. 3 was calculated to be $41.63 \pm 0.54 \%$.

In the study carried out by Beemnet et al. [11] to determine the oil contents of the Ethiopian jatropha populations from five regional states of the country, it was found that the averaged oil extracted by a Soxhlet extractor using hexane as solvent ranged from 29.88 to $34.34 \%$. The authors also reported that the oil obtained from jatropha seed collected from the Southern Nation Nationalities and Peoples Regional State (from southern Ethiopia), by extracting using a Soxhlet extractor with thimble, varied from 31.18 to $35.91 \%$, and with average of $34.34 \%$. Thus, the average oil obtained in the present experiments from all seeds collected from southern Ethiopia $(41.63 \pm 0.54 \%)$ was larger than the values reported [11].

The larger average oil obtained in the present experiment compared to the previously reported value might be caused by the difference in the pretreatment of the seeds for oil extraction, the thickness of thimbles used, and the particle sizes of the CS used for the experiments. In the present study, the whole jatropha seeds were dried before crushing at $80^{\circ} \mathrm{C}$ until no more moisture loss occurred, and the filter used was thimble with single thickness $(37 \times 130 \mathrm{~mm})$. However, in the oil extraction by Beemnet et al. [11], no seed drying procedure and the thickness of the extraction thimble used were reported. By extracting jatropha seed kernel from northern Ethiopia, using a Soxhlet extractor and petroleum ether as solvent, Amabye and Bezabh [26] obtained the oil yield of $42.19 \%$ which was also less than the mean oil extracted from Chali $(45.79 \pm 0.54 \%)$, Dimeka $(43.91 \pm 0.71 \%)$, and Dana (43.29 $\pm 0.12 \%$ ) seed collections in of the present study.

Table 4 shows the amount of oil (\%) extracted from Kako collection by ethanol, using thicker thimble $(40 \times 150 \mathrm{~mm})$ and cotton for different extraction time (for different number of cycles of washes). As it can be seen from Table 4, oil extracted with cotton for five cycles of washes $(28.17 \%)$ was found to be the largest. When the cycle of wash increased from five to ten using thimble with the same thickness, the amount of oil extracted (\%) increased from 11.99 to $26.73 \%$. This shows that the amount of oil (\%) extracted increased to 
more than double when the number of washing cycles increased from five to ten.

Concerning the increment of jatropha oil yield with extraction time (the number of cycles of washes in the current work), Santos et al. [19] reported that the oil yield increased with the time of extraction until reaching equilibrium (saturation of the solvent) regardless of the temperatures used, and the moisture contents and average particle sizes of the extracted seeds. In the study of oil extraction from jatropha seed using hexane and petroleum ether as solvent, Sayyar et al. [18] also reported that oil yield increased with extraction time until the optimum extraction time of $8 \mathrm{~h}$ was reached. Moreover, in the extraction of oil from spent coffee grounds, the highest oil yield was achieved at $8 \mathrm{~h}$ of solvent extraction, but the yield was considerably low when the duration of extraction was less than $2 \mathrm{~h}$ [39]. The reason for this could be that the short duration of extraction might not allow sufficient time for the recirculating solvent to extract the total available oil from the feedstock [39, 40].

As it can be seen from Table 4, the extraction with cotton produced larger oil yield only with five cycles of washes compared to the thimble. Thus, using cotton could shorten the extraction time by reducing the number of cycles of washes needed to extract the oil available for extraction using the extraction method used. Cotton could also be easily available and cheaper than the extraction thimbles. However, in the extraction with cotton, the cycles of washes (particularly, the time taken for the consecutive cycles of washes to occur) were observed to be less uniform compared to that of extraction thimble in the successive batches of extraction. This might occur due to the difference in thickness and compression of the cotton placed in the Soxhlet column for the respective batches of extraction. Moreover, cotton did also absorb more solvents than thimble and resulted in less solvents recovery. Averagely, about $10 \%$ of the solvent was lost in the case of extraction with cotton compared to the amount of solvent recovered in the extraction using thimble.

Fig. 4 Mean oil extracted from Salmene $_{2}$ stored at room temperature $\left(20^{\circ} \mathrm{C}\right)$, cool temperature $\left(4^{\circ} \mathrm{C}\right)$, and freezing temperature $\left(-18^{\circ} \mathrm{C}\right)$. Bars show means $\pm \mathrm{SE}$

\section{Oil Extraction from Seeds Stored at Different Temperatures}

Figure 4 shows the mean oil extracted from Salmene 2 seed collection that was stored at three different temperatures. As it can be observed from Fig. 4, the mean percentage oil extracted from Salmene 2 stored at $-18{ }^{\circ} \mathrm{C}(43.55 \pm 1.46 \%)$ was found to be slightly higher than those of the seeds stored at $4{ }^{\circ} \mathrm{C}$ $(43.09 \pm 1.32 \%)$ and $20{ }^{\circ} \mathrm{C}(41.51 \pm 1.89 \%)$. However, the oil extracted from the seeds stored at the three different temperatures did not significantly differ $(p \leq 0.05)$.

From the study of the effects of jatropha seed storage on the quantity of oil, Sushma [41] reported that the seed stored at $5{ }^{\circ} \mathrm{C}$ gave the highest amount of oil $(29.12 \%)$ after 15 months of storage compared to $22.11,17.39$, and $12.27 \%$ oil contents for those seeds stored at room temperature $\left(15.5^{\circ} \mathrm{C}\right), 0^{\circ} \mathrm{C}$, and $-5^{\circ} \mathrm{C}$, respectively. However, in the present study, there was no such significant difference among the amount of oil obtained from the seeds stored at the three different temperatures. The results of this experiment demonstrated that all the seed samples stored at three different temperatures gave almost similar amount of oil, and thus, the storage temperatures might not significantly affect the amount of oil in the seed samples and/or the process of oil extraction.

\section{Physico-chemical Analysis of the Oils}

Experimental values for some properties of the oil of Chali collection (Chali oil) and mixed oil samples and the values reported in literature for the same parameters of oils from different origin (countries) are presented in Table 5. As it can be seen from Table 5, the acid value and free fatty acids for Chali oil and the mixed oil samples were found to be 1.32 \pm 0.14 and $2.12 \pm 0.15 \mathrm{mg} \mathrm{KOH} / \mathrm{g}$ and $0.66 \pm 0.07$ and $1.06 \pm$ $0.07 \%$, respectively. Acid value indicates the amount of FFA found in fat or oil, and it provides information about how much generation of free fatty acids has taken place. The age of oil sample and oil exposure to atmospheric oxygen could increase acid value of the oil $[42,43]$. The higher acid value

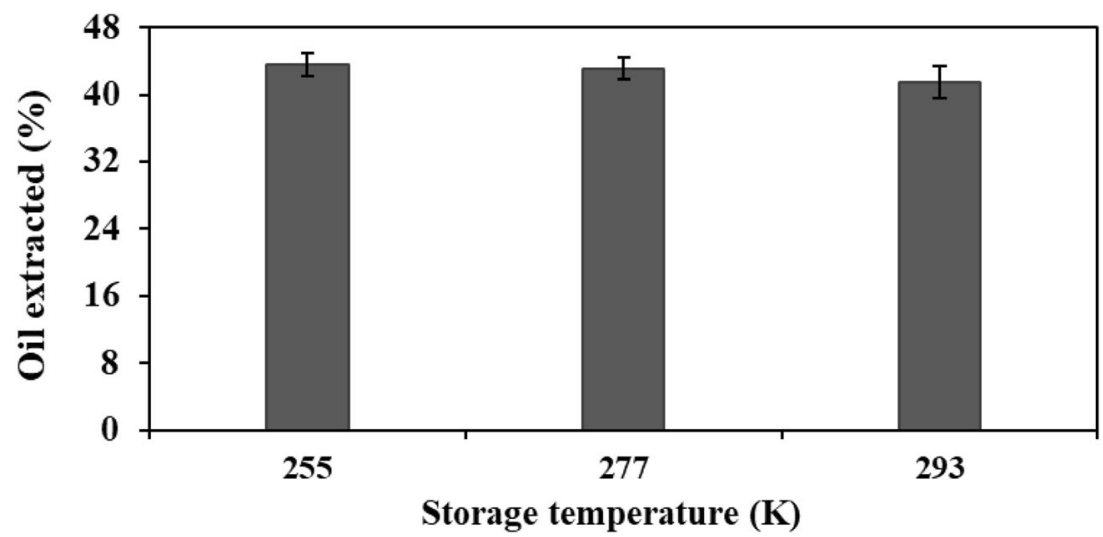


and $\%$ FFA for the mixed oil compared to that Chali oil in the present study could be due to the age of the oil as mixed oil contained oils from thirteen different jatropha seed collections that were extracted in 2016 and 2017 while Chali oil was extracted from the seed that was collected in 2017.

Compared to the values of the acid vale and \%FFA of jatropha oil reported in literature and listed in Table 5, the values obtained for Chali oil in the current study were lower than that of all the values reported, except for the one from South Africa. The reported values of acid value and \%FFA for the oil of jatropha seeds from South Africa were $0.9 \mathrm{mg}$ $\mathrm{KOH} / \mathrm{g}$ and of $0.4 \%$, respectively [45]. However, the values of the same parameters for the mixed oil from the present experiment were found to be larger than that of the values reported for jatropha oil extracted from jatropha seeds of Malaysian [44], Ethiopian [26], South African [45], and Indian [45] origins. As mentioned earlier, the larger acid value and \%FFA of the mixed oil of the present study could be due to the age of the seeds from which the component oils of the mixed oil were extracted. Differences in the acid value and \%FFA the jatropha oils from different seeds might also be due to the differences in maturation stage of the fruits from which the seeds were collected [30]. Mazumdar et al. [48] mentioned that among all the fuel properties studied for jatropha oil collected from different geographical location of world, acid value is found to vary widely, and the causes of such variation in the acid value may be due to some genetic variations, differences in seed maturation stages, seed storage, and edaphic condition of the regions [49].

Technically, acid value is the mass of potassium hydroxide $(\mathrm{KOH})$ in milligrams that is needed to neutralize $1 \mathrm{~g}$ of chemical substance. Larger acid value shows the presence of more amount of free fatty acid (FFA) in the oil and the presence of which interferes biodiesel production, particularly, when basic catalysts are used in the transesterification process. The yield of biodiesel is dependent on the acid value as oil with lower acid value produces higher biodiesel throughput [42]. From the results of the current study, Chali oil sample, which had lower acid value than that of the mixed oil, was found relatively to be a better feedstock to be used in base-catalyzed transesterification process.

The iodine value of Chali oil and mixed oil samples were found to be $116.02 \pm 3.50$ and $109.24 \pm 0.05 \mathrm{~g} / 100 \mathrm{~g}$, respectively, and thus, the value for Chai oil was larger than that of the mixed oil. Compared to the literature values listed in Table 5, the iodine values for both Chali oil and mixed oil samples were moderate, and within the range of the values reported in the listed literature.

The iodine value is a measure of the degree of unsaturation of the oil and the larger the iodine value, the greater the degree of unsaturation $[27,50]$. The maximum iodine value for biodiesel is $120 \mathrm{~g} / 100 \mathrm{~g}$ according to the European EN 14214 specification. The maximum limit of 
Table 6 Energy content of the selected de-oiled residue of jatropha seeds after oil extraction with different solvents

No. Description for the de-oiled seed residues
Codes used for the seed residues
Upper/gross calorific values $(\mathrm{MJ} / \mathrm{kg})^{\mathrm{d}}$

$1 \quad$ Kako WS, dried, crushed, and extracted by thicker thimble and ethanol with 5 washes

2 Kako WS, dried, crushed, and extracted by hexane

KWDCS/TEth5

24.03

Awwaaragamaa WS, dried, crushed, and extracted by hexane

KkWSDCS/Hex

20.72

Dimeka WS (from dried fruit), dried, crushed, and extracted by hexane

AwWSDCS/Hex

20.07

Salmene $_{2}$ CS, dried, and extracted by hexane

DkWS(d)DCS/Hex

19.77

$\mathrm{S}_{2} \mathrm{CSD} / \mathrm{Hex}$

19.67

Salmene $_{2}$ stored at $-18{ }^{\circ} \mathrm{C}$, WS dried, crushed, and extracted by hexane

Salmene $_{3}$, crushed seed, dried, and extracted by hexane

Gerbi CS, dried, and extracted by hexane

$\mathrm{S}_{2} \mathrm{WS}\left(-18^{\circ} \mathrm{C}\right) \mathrm{DCS} / \mathrm{Hex}$

19.66

$\mathrm{S}_{3} \mathrm{CSD} / \mathrm{Hex}$

19.52

GCSD/Hex

19.50

ChWSDCS/Hex

19.47

DkWS(y)DCS/Hex

19.44

$\mathrm{S}_{3}$ WSDCS/Hept

19.40

MWSDCS/Hex

19.39

ShCSD/Hex

19.30

$\mathrm{S}_{3}$ WSDCS/DE

19.22

$\mathrm{S}_{2} \mathrm{WS}(\mathrm{RT}) \mathrm{DCS} / \mathrm{Hex}$

18.93

Salmene $_{2}$ WS stored at room temperature, dried, crushed, and extracted by hexane

16 Salmene $_{2}$ WS, dried, crushed, and extracted by hexane

$\mathrm{S}_{2} \mathrm{WDCS} / \mathrm{Hex}$

18.84

$\mathrm{S}_{3} \mathrm{WSDCS} / \mathrm{Hex}$

18.81

DnWSDCS/Hex

18.77

$\mathrm{S}_{2} \mathrm{WS}\left(4^{\circ} \mathrm{C}\right) \mathrm{DCS} / \mathrm{Hex}$

18.57

19.64

${ }^{\mathrm{d}}$ Calorific values are arranged from the largest (number 1) to the smallest (number 19)

unsaturation is necessary because heating higher unsaturated fatty acid results in polymerization of glycerides, and this could lead to the formation of deposits and deterioration of the lubricating properties [51]. Higher unsaturated fatty acids have also a negative impact on oil stability [45]. Vegetable oil with iodine value between 100 and 130 belongs to the groups of semi-drying oil. This group of oil absorbs atmospheric oxygen slowly, partially hardens, and forms a soft film after prolonged exposure to air [27, 43]. Accordingly, jatropha oils are classified under semi-drying oil group, and the higher iodine value of jatropha oil is caused by high content of unsaturated fatty acid such as oleic acid and linoleic acid [51]. Thus, the iodine values obtained for both Chali oil and mixed oil samples in the current study suggested that both oils were classified under semi-drying oil group and could also be used as the feedstock for biodiesel as their iodine value were not exceeding the maximum values for biodiesel in the European EN 14214 specification.

Saponification is the hydrolysis of fats and oils in the presence of alkaline solution such as potassium hydroxide or caustic soda to produce glycerol and the corresponding salt of fatty acids. Saponification value of an oil is the number of $\mathrm{mg}$ of potassium hydroxide required to saponify $1 \mathrm{~g}$ of oil/fat. It indicates the nature of fatty acids available in triacylglycerol.
The longer the carbon chain of the fat hydrolyzed, the reduced the quantity of acid liberated per gram of sample and hence the reduced the saponification value of such oil sample [42]. As it is presented in Table 5, the saponification values of Chali oil and mixed oil were $191.40 \pm 3.11$ and $205.77 \pm 3.81 \mathrm{mg}$ $\mathrm{KOH} / \mathrm{g}$, respectively. This shows that the saponification value for the mixed oil was larger than that of Chaali oil. The saponification values of both Chali and mixed oil samples were high and in the range of the literature values listed in Table 5 for jatropha oils of different origin. According to Rania et al. [47], jatropha oil is usually associated with high saponification value due to the fact that the oil contains normal triglycerides, and such oils with high saponification numbers are very useful in production of liquid soap and shampoo industries [51].

Density is the mass per unit volume of the oil at a particular temperature. The density of vegetable oil is lower than that of water and the differences between the densities of vegetable oils are quite small, particularly among the common vegetable oils [47]. The densities of Chali oil $(0.906 \pm 0.001 \mathrm{~g} / \mathrm{ml})$ and that of the mixed oil $(0.9104 \pm 0.001 \mathrm{~g} / \mathrm{ml})$ of the present study were about equal. The values for both oil samples were in line with the literature values listed in Table 5, except for the density reported for the jatropha oil from Sudan $(0.943 \mathrm{~g} / \mathrm{ml})$, which was reasonably higher than both experimental values. 


\section{Calorific Values of the Seed Residues}

The energy contents of selected de-oiled jatropha seed residues were determined and compared with each other and the values from literature. Table 6 shows the gross calorific value of the de-oiled seed residues left after oil extraction using different solvents. As it can be seen from Table 6, the upper calorific values (gross calorific values) of the analyzed samples ranged from 18.57 to $24.03 \mathrm{MJ} / \mathrm{kg}$, and with an average of $19.64 \mathrm{MJ} / \mathrm{kg}$. The gross calorific values of all the de-oiled seed residues analyzed in the present study and their average were in the range of the gross calorific values (14.3-25.4 MJ/ $\mathrm{kg}$ ) determined by Gravalos et al. [34] for different agroforestry species and bio-based industry residues.

In the current experiments, the largest gross calorific value $(24.03 \mathrm{MJ} / \mathrm{kg}$ ) was obtained from the residue of Kako WS that was dried, crushed, and extracted by thicker thimble and ethanol, by employing five cycles of washes (KWDCS/TEth5). The smallest gross calorific value $(18.57 \mathrm{MJ} / \mathrm{kg})$ was recorded in the case of the residue of Salmene 2 WS that was stored at $4{ }^{\circ} \mathrm{C}$, dried, crushed, and extracted with hexane $\left(\mathrm{S}_{2} \mathrm{WS}\left(4^{\circ} \mathrm{C}\right) \mathrm{DCS} / \mathrm{Hex}\right)$. The second smallest gross calorific value $(18.77 \mathrm{MJ} / \mathrm{kg})$ was also obtained from the de-oiled residue of Dana seed collection that was extracted by hexane and cotton by applying five cycles of washes (DnWSDCS/Hex).

As it is shown in Table 6, the de-oiled seed residue KWDCS/TEth5, the residue that produced the largest gross calorific value $(24.03 \mathrm{MJ} / \mathrm{kg})$, was the residue of the seeds from which only $11.99 \%$ oil (the lowest amount of oil) was extracted (Table 4). The de-oiled seed residue that produced the second smallest gross calorific value $(18.77 \mathrm{MJ} / \mathrm{kg})$ was also the de-oiled seed residue of the seeds from which $48.29 \%$ oil (the largest amount of oil) was extracted (DnWSDCS/Hex) (Table 2). These results showed that the de-oiled seed residues that were produced after the extraction of the smallest amount of oil (\%) gave the largest gross calorific value and vice versa. This suggested that the residual oil in de-oiled seed residue could impact their gross calorific values. However, the gross calorific values of the other de-oiled seed residues (Table 6) did not consistently follow the same trend. This might be due to the interactions of other factors such as the organic molecules other than the residual oil and the ash contents, which can affect the gross calorific value of the de-oiled seed residues [34].

The average gross calorific value of jatropha seed residues found from the present experiment $(19.64 \mathrm{MJ} / \mathrm{kg})$ was in accordance with the value reported for the cake of jatropha seed by Kavalek et al. [9], which was $19.11 \mathrm{MJ} / \mathrm{kg}$. However, it was greater than the values $18.76,18.2$, and $17.7 \mathrm{MJ} / \mathrm{kg}$, which were reported by Steinbrück et al. [52], Achten et al. [53], and Sharma and Sheth [54], respectively. As the cake of jatropha seed has very low moisture content and its residual oil content does not tend to take in water, it is suitable for direct combustion [9]. Moreover, it was reported that the gross calorific values for the jatropha seed (with $0 \%$ moisture content) and jatropha oil were 20.85 and $37.83 \mathrm{MJ} / \mathrm{kg}$, respectively [55].

Elemental composition (particularly due to difference in carbon content as it is the main energy source), ash (noncombustible material), and moisture contents are the main factors that determine the gross calorific values of crop residues [34]. Accordingly, seeds and kernels have higher gross calorific values than the seed shell, husks, cakes, and other residues as the seeds and kernels have higher unit mass and higher lipid content compared to the residues [34]. Concerning the conversion of residues of jatropha such as de-oiled seed cakes, seed shell, fruit husk, and pruned twigs to useful energy sources, Steinbrück et al. [52] wrote that the conversion of these residues into marketable products would contribute to broadening the circumstances under which the jatropha crop is profitable.

\section{Conclusion}

In this paper, the oil contents of thirteen different jatropha seed collections from Ethiopia were determined with Soxhlet extraction, using hexane as solvent. Cotton and thimble were used as filter for the extractions. The properties of Chali and mixed oils and the calorific values of the selected de-oiled seed residues were also determined. In the extraction with cotton, the largest amount of oil was obtained from Dana seed collection whereas in the case of extraction with thimble, the largest oil yield was found from Chali seed collection. The maximum and higher average oil yields were found from the seed collections from southern Ethiopia. The study suggested that Chali seed oil is more suitable for alkaline-catalyzed biodiesel production as its acid value and free fatty acid contents were lower than that of the mixed oil. The iodine values of both Chali and mixed oils did not exceed the maximum standard value for biodiesel according to the EN 14214 specification, and thus, both oils could be used as the biodiesel feedstock. The average gross calorific values of the de-oiled jatropha seed residues were found to be $19.64 \mathrm{MJ} / \mathrm{kg}$. Thus, the seed residues could be used as the source of heat.

Funding This work was supported by the EnPe/NORHED of Norad project entitled "Research and Capacity Building in Clean and Renewable Bioenergy in Ethiopia," with Agreement No. 2015/8397 at the Norwegian University of Life Sciences (NMBU), Norway. Open Access funding provided by Norwegian University of Life Sciences.

\section{Compliance with Ethical Standards}

Conflict of Interest The authors declare that they have no conflict of interest. 
Open Access This article is licensed under a Creative Commons Attribution 4.0 International License, which permits use, sharing, adaptation, distribution and reproduction in any medium or format, as long as you give appropriate credit to the original author(s) and the source, provide a link to the Creative Commons licence, and indicate if changes were made. The images or other third party material in this article are included in the article's Creative Commons licence, unless indicated otherwise in a credit line to the material. If material is not included in the article's Creative Commons licence and your intended use is not permitted by statutory regulation or exceeds the permitted use, you will need to obtain permission directly from the copyright holder. To view a copy of this licence, visit http://creativecommons.org/licenses/by/4.0/.

\section{References}

1. Abdelgadir HA, Van Staden J (2013) Ethnobotany, ethnopharmacology and toxicity of Jatropha curcas L. (Euphorbiaceae): a review. S Afr J Bot 88:204-218. https://doi. org/10.1016/j.sajb.2013.07.021

2. Islam A, Yaakob Z, Anuar N (2011) Jatropha: a multipurpose plant with considerable potential for the tropics. Sci Res Essays 6(13): 2597-2605. https://doi.org/10.5897/SRE10.611

3. Abobatta W (2019) Jatropha curcas: an overview. J Adv Agric 10: 1650-1656. https://doi.org/10.24297/jaa.v10i0.8145

4. Waghmare T, Bhandare P, Belladal B, Londonkar R (2017) Physiological characterization of Jatropha curcus L. a biofuel plant from Hyderabad Karnataka Region, India. Int J Curr Microbiol App Sci 6(8):1344-1355. https://doi.org/10.20546/ijcmas.2017. 608.164

5. El Bassam N (2010) Handbook of bioenergy crops: a complete reference to species, development and applications. Earthscan, London, UK. https://nishat2013.files.wordpress.com/2013/11/ handbook-of-bioenergy-crops.pdf

6. Sulaiman Y, Saidat OG, Maryam I, Abdulwahab G (2016) Extraction of oil from Jatropha seed kernels: optimization and characterization. Int J ChemTech Res 9(5):758-770

7. Wakandigara A, Nhamo L, Kugara J (2013) Chemistry of phorbol ester toxicity in Jatropha curcas seed-a review. Int J Biochem Res Rev 3(3):146-161. https://doi.org/10.9734/IJBCRR/2013/2956

8. Atabani AE, Silitonga AS, Ong HC, Mahlia TMI, Masjuki HH, Badruddin IA, Fayaz H (2013) Non-edible vegetable oils: a critical evaluation of oil extraction, fatty acid compositions, biodiesel production, characteristics, engine performance and emissions production. Renew Sust Energ Rev 18:211-245. https://doi.org/10.1016/j. rser.2012.10.013

9. Kavalek M, Havrland B, Ivanova T, Hutla P, Skopec P (2013) Utilization of Jatropha curcas L. seed cake for production of solid biofuels. Eng Rural Dev 23:536-540

10. No S-Y (2011) Inedible vegetable oils and their derivatives for alternative diesel fuels in CI engines: a review. Renew Sust Energ Rev 15(1):131-149. https://doi.org/10.1016/j.rser.2010.08.012

11. Beemnet MK, Damtew Z, Guteta N, Philipos M, BIsrat D, Asaminew G, Tadese S, Nurhusain H, Haile F, Abate S, Balcha M, Mekonnen B (2016) Oil content, fruit and seed characteristics Ethiopian Jatropha (Jatropha curacas L.) provenances. Int J Adv Biol Biomed Res 4(1):77-88. https://doi.org/10.18869/IJABBR. 2016.77

12. Derkyi NSA, Sekyere D, Oduro KA (2014) Variations in oil content and biodiesel yield of Jatropha curcas from different agroecological zones of Ghana. Int J Renew Sustain Energy I 3(4):7681. https://doi.org/10.11648/j.ijrse.20140304.11
13. Singer SD, Zou J, Weselake R (2016) Abiotic factors influence plant storage lipid accumulation and composition. Plant Sci 243: 1-9. https://doi.org/10.1016/j.plantsci.2015.11.003

14. Kaushik N, Kumar K, Kumar S, Kaushik N, Roy S (2007) Genetic variability and divergence studies in seed traits and oil content of Jatropha (Jatropha curcas L.) accessions. Biomass Bioenergy 31(7): 497-502. https://doi.org/10.1016/j.biombioe.2007.01.021

15. Danlami JM, Arsad A, Zaini MAA, Sulaiman H (2014) A comparative study of various oil extraction techniques from plants. Rev Chem Eng 30(6):605-626. https://doi.org/10.1515/revce-20130038

16. Naik SN, Goud VV, Rout PK, Dalai AK (2010) Production of first and second generation biofuels: a comprehensive review. Renew Sust Energ Rev 14(2):578-597. https://doi.org/10.1016/j.rser.2009. 10.003

17. Shivani P, Khushbu P, Faldu N, Thakkar V, Shubramanian R (2011) Extraction and analysis of Jatropha curcas L. seed oil. Afr J Biotechnol 10(79):18210-18213. https://doi.org/10.5897/AJB11. 776

18. Sayyar S, Abidin ZZ, Yunus R, Muhammad A (2009) Extraction of oil from Jatropha seeds-optimization and kinetics. Am J Appl Sci 6(7):1390-1395. https://doi.org/10.3844/ajassp.2009.1390.1395

19. Santos SB, Martins MA, Caneschi AL, Aguilar PRM, Coimbra JSR (2015) Kinetics and thermodynamics of oil extraction from Jatropha curcas L. using ethanol as a solvent. Int J Chem Eng 2015:1-9. https://doi.org/10.1155/2015/871236

20. Finney K, Pomeranz Y, Hoseney R (1976) Effects of solvent extraction on lipid composition, mixing time, and bread loaf volume. Cereal Chem 53(3):383-388

21. Straccia MC, Siano F, Coppola R, La Cara F, Volpe MG (2012) Extraction and characterization of vegetable oils from cherry seed by different extraction processes. Chem Eng Trans 27:391-396. https://doi.org/10.3303/CET1227066

22. Bhargavi G, Rao PN, Renganathan S Review on the extraction methods of crude oil from all generation biofuels in last few decades. In: IOP Conference Series: Materials Science and Engineering, Vol 1, IOP Publishing, p 012024. https://doi.org/10. 1088/1757-899X/330/1/012024

23. Zarnowski R, Suzuki Y (2004) Expedient Soxhlet extraction of resorcinolic lipids from wheat grains. J Food Compos Anal 17(5): 649-663. https://doi.org/10.1016/j.jfca.2003.09.007

24. Hibbert S, Welham K, Zein SH (2019) An innovative method of extraction of coffee oil using an advanced microwave system: in comparison with conventional Soxhlet extraction method. SN Appl Sciences 1(11):1467. https://doi.org/10.1007/s42452-019-1457-5

25. Keneni YG, Marchetti JM (2019) Temperature and pretreatment effects on the drying of different collections of Jatropha curcas L. seeds. SN Appl Sciences 1(8):943. https://doi.org/10.1007/s42452019-0969-3

26. Amabye TG, Bezabh AM (2015) Physicochemical characterization and phytochemical screening of Jatropha curcas L. seed oil cultivated in Tigray Ethiopia. Adv Biochem 3(3):35-39. https://doi.org/ 10.11648/j.ab.20150303.11

27. Subroto E (2015) Optimization of Jatropha curcas pure plant oil production. $\mathrm{PhD}$ thesis, University of Groningen, Netherlands

28. Sayyar S, Abidin ZZ, Yunus R (2012) Optimisation of solid liquid extraction of jatropha oil using petroleum ether. Asia Pac J Chem Eng 8:331-338. https://doi.org/10.1002/apj.1664

29. Zavala-Hernández J, Córdova-Téllez L, Martínez-Herrera J, Molina-Moreno J (2015) Physiological quality and chemical profile of developing Jatropha curcas seeds. Seed Sci Technol 43(3): 433-444. https://doi.org/10.15258/sst.2015.43.3.12

30. Jonas M, Ketlogetswe C, Gandure J (2018) Influence of jatropha fruit maturity on seed oil yield, composition and heat of combustion of derived biodiesel. Energy Power Eng 10(03):77-86. https://doi. org/10.4236/epe.2018.103006 
31. Capello C, Fischer U, Hungerbühler KJGC (2007) What is a green solvent? A comprehensive framework for the environmental assessment of solvents. Green Chem 9(9):927-934. https://doi.org/10. 1039/B617536H

32. Asmare M, Gabbiye N (2014) Synthesis and characterization of biodiesel from castor bean as alternative fuel for diesel engine. Am J Energy Eng 2(1):1-15. https://doi.org/10.11648/j.ajee. 20140201.11

33. Ogbunugafor H, Eneh F, Ozumba A, Igwo-Ezikpe M, Okpuzor J, Igwilo I, Adenekan S, Onyekwelu O (2011) Physico-chemical and antioxidant properties of Moringa oleifera seed oil. Pak J Nutr 10(5):409-414. https://doi.org/10.3923/pjn.2011.409.414

34. Gravalos I, Xyradakis P, Kateris D, Gialamas T, Bartzialis D, Giannoulis K (2016) An experimental determination of gross calorific value of different agroforestry species and bio-based industry residues. Nat Res Forum 7(01):57-68. https://doi.org/10.4236/nr. 2016.71006

35. Atabani AE, Silitonga AS, Badruddin IA, Mahlia T, Masjuki H, Mekhilef S (2012) A comprehensive review on biodiesel as an alternative energy resource and its characteristics. Renew Sust Energ Rev 16(4):2070-2093. https://doi.org/10.1016/j.rser.2012. 01.003

36. Ginwal H, Rawat P, Srivastava R (2004) Seed source variation in growth performance and oil yield of Jatropha curcas Linn. in central India. Silvae Genet 53(1-6):186-192. https://doi.org/10.1515/sg2004-0034

37. Santoso BB, Budianto A, Aryana IM (2012) Seed viability of Jatropha curcas in different fruit maturity stages after storage. Nusant Biosci 4(3):113-117. https://doi.org/10.13057/nusbiosci/ n040305

38. Omosuli S, Oloye D, Ibrahim T (2017) Effect of drying methods on the physicochemical properties and fatty acid composition of Moringa seeds oil. Arch Food Nutr Sci 1:027-032. https://doi.org/ 10.29328/journal.afns. 1001005

39. Efthymiopoulos I, Hellier P, Ladommatos N, Kay A, MillsLamptey B (2019) Effect of solvent extraction parameters on the recovery of oil from spent coffee grounds for biofuel production. Waste Biomass Valori 10(2):253-264. https://doi.org/10.1007/ s12649-017-0061-4

40. Lawson OSOA, Ologunagba FO, Ojomo AO (2010) Evaluation of the parameters affecting the solvent extraction of soybean oil. ARPN J Eng Appl Sci 5(10):51-55

41. Sushma B (2014) Analysis of oil content of Jatropha curcas seeds under storage conditions. J Environ Biol 35:571-575

42. Mohammed NI, Kabbashi NA, Alam MZ, Mirghani ME (2014) Jatropha curcas oil characterization and its significance for feedstock selection in biodiesel production. Paper presented at the $5^{\text {th }}$ International Conference on Food Engineering and Biotechnology, Vol. 65, IACSIT Press, Singapore, pp 57-62

43. Umaru M, Aberuagba F (2012) Characteristics of a typical Nigerian Jatropha curcas oil seeds for biodiesel production. Res J Chem Sci 2(10):7-12
44. Salimon J, Abdullah R (2008) Physicochemical properties of Malaysian Jatropha curcas seed oil. Sains Malays 37(4):379-382

45. Islam AA, Yaakob Z, Anuar N, Primandari SRP, Osman M (2012) Physiochemical properties of Jatropha curcas seed oil from different origins and candidate plus plants (CPPs). J Am Oil Chem Soc 89(2):293-300. https://doi.org/10.1007/s11746-011-1908-7

46. Kadry GA (2015) Biodiesel production from jatropha seeds. Am J Chem Eng 3(6):89-98. https://doi.org/10.11648/j.ajche.20150306. 13

47. Rania DM, Albasha MEME, Abadi RSM, El Siddig MA (2015) Comparative studies on physicochemical properties and fatty acids composition of seed oil of Jatropha curcas and Jatropha glauca. Int J Tech Res Appl 3(4):407-412

48. Mazumdar P, Dasari SR, Borugadda VB, Srivasatava G, Sahoo L, Goud VV, Biorefinery (2013) Biodiesel production from high free fatty acids content Jatropha curcas L. oil using dual step process. Biomass Conv Bioref 3 (4):361-369. https://doi.org/10.1007/ s13399-013-0077-3

49. de Oliveira JS, Leite PM, de Souza LB, Mello VM, Silva EC, Rubim JC, Meneghetti SM, Suarez PAJB, Bioenergy (2009) Characteristics and composition of Jatropha gossypiifoliaand Jatropha curcas L. oils and application for biodiesel production. Biomass Bioenergy 33(3):449-453. https://doi.org/10.1016/j. biombioe.2008.08.006

50. Nzikou J, Kimbonguila A, Matos L, Loumouamou B, PambouTobi N, Ndangui C, Abena A, Silou T, Scher J, Desobry S (2010) Extraction and characteristics of seed kernel oil from mango (Mangifera indica). Res J Env Earth Sci 2(1):31-35

51. Akbar E, Yaakob Z, Kamarudin SK, Ismail M, Salimon J (2009) Characteristic and composition of Jatropha curcas oil seed from Malaysia and its potential as biodiesel feedstock feedstock. Eur J Sci Res 29(3):396-403

52. Steinbrück J, Tavakkol S, Francis G, Bockhorn H (2019) Jatropha potential of biomass steam processing to convert crop residues to bio-coal and thus triple the marketable energy output per unit plantation area. Ind Crop Prod 136:59-65. https://doi.org/10.1016/j. indcrop.2019.04.065

53. Achten W, Verchot L, Franken YJ, Mathijs E, Singh VP, Aerts R, Muys B (2008) Jatropha bio-diesel production and use. Biomass Bioenergy 32(12):1063-1084. https://doi.org/10.1016/j.biombioe. 2008.03.003

54. Sharma R, Sheth PN (2015) Thermo-chemical conversion of jatropha deoiled cake: pyrolysis vs. gasification. Int J Chem Eng Appl 6(5):376-380. https://doi.org/10.7763/IJCEA.2015.V6.513

55. Augustus G, Jayabalan M, Seiler G (2002) Evaluation and bioinduction of energy components of Jatropha curcas. Biomass Bioenergy 23(3):161-164. https://doi.org/10.1016/S09619534(02)00044-2

Publisher's Note Springer Nature remains neutral with regard to jurisdictional claims in published maps and institutional affiliations. 